\title{
molecules
}

ISSN 1420-3049

www.mdpi.com/journal/molecules

Review

\section{Click Chemistry for the Synthesis of RGD-Containing Integrin Ligands}

\section{Matteo Colombo $^{1, *}$ and Aldo Bianchi ${ }^{2}$}

1 NiKem Research, via Zambeletti 25, 20021 Baranzate, Milan, Italy

2 Consorzio Interdisciplinare di Studi Biomolecolari ed Applicazioni Industriali (CISI), Via Fantoli 16/15, 20138 Milan, Italy; E-Mail: aldo.bianchi@cisiscrl.com (A.B.)

* Author to whom correspondence should be addressed;

E-Mail:matteo.colombo@nikemresearch.com; Fax: +39-235694-7606.

Received: 1 December 2009; in revised form: 19 December 2009 / Accepted: 31 December 2009 / Published: 6 January 2010

\begin{abstract}
In the last few years click chemistry reactions, and in particular coppercatalyzed cycloadditions, have been used intensively for the preparation of new bioconjugate molecules and materials applicable to biomedical and pharmaceutical areas. This review will be focused on conjugates of the tripeptide Arg-Gly-Asp formed by means of click chemistry reactions. This sequence is a well known binding motif for specific transmembrane proteins and is involved in cellular adhesion to the extracellular matrix, allowing the selective recognition of the biomolecule or polymer in which it is incorporated.
\end{abstract}

Keywords: click chemistry; RGD; pseudopeptide; biomaterials; integrins

Abbreviations: alanine (Ala, A), arginine (Arg, R), asparagine (Asn, N), aspartic acid (Asp, D), cysteine (Cys, C), glycine (Gly, G), glutamic acid (Glu, E), histidine (His, H), isoleucine (Ile, I), leucine (Leu, L), lysine (Lys, K), methionine, (Met, M), phenylalanine (Phe, F), proline (Pro, P), serine (Ser, S), threonine (Thr, T), tyrosine (Tyr, Y). The symbols in capital letters indicate natural L-aminoacids and the symbols in minuscule letters indicate D-aminoacids. 


\section{Introduction}

"The reactions must be modular, wide in scope, give very high yields, generate only inoffensive byproducts that can be removed by nonchromatographic methods, and be stereospecific. The required process characteristics include simple reaction conditions (ideally, the process should be insensitive to oxygen and water), readily available starting materials and reagents, the use of no solvent or a solvent that is benign (such as water) or easily removed, and simple product isolation.” These are the set of general criteria indicated by Kolb, Finn and Sharpless in 2001 to define a "click chemistry" reaction [1].

Carbon-heteroatom bond forming reactions and in particular cycloaddition reactions, nucleophilic ring-opening reactions, carbonyl chemistry of the "non-aldol" type, and additions to carbon-carbon multiple bonds are the typical examples of these kind of near-perfect chemical transformations.

Among the aforementioned type of click transformations, undoubtedly, the premier click chemistry reaction in terms of applications and spread is the $\mathrm{Cu}(\mathrm{I})$-catalyzed alkyne-azide cycloaddition (CuAAC). This copper-catalyzed version of the Huisgen 1,3-dipolar cycloaddition demonstrates all the necessary characteristics of a click reaction: prompt accessibility to starting materials, running and purification simplicity, very high yields, complete regioselectivity and widespread applicability (Scheme 1). For these reasons it is often defined erroneously as the "click chemistry" reaction. Moreover, 1,4-substituted 1,2,3-triazoles, the products of CuAAC, are able to function as rigid linking units that mimic the atom placement and electronic properties of an amide bond without the same susceptibility to enzymatic hydrolytic cleavage [2].

Scheme 1. Copper-catalyzed alkyne-azide cycloaddition (CuAAC).

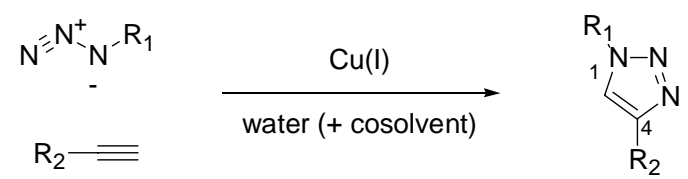

Since 2001 a plethora of papers involving click reactions has been published in various areas of synthetic chemistry, including drug discovery, biomolecules, macromolecules and materials. In this review we would like to focus our attention on recent advances of the applications of click chemistry reactions for the synthesis of molecules and materials bearing the tripeptide arginine-glycine-aspartic acid (Arg-Gly-Asp or RGD).

The RGD sequence (Figure 1) has been identified as an essential binding motif for at least seven integrin receptors [3-4]. Integrins are heterodimeric $(\alpha-\beta)$ transmembrane proteins expressed at the cell surface and involved in cellular adhesion to the extracellular matrix [5-6]. They stimulate vascular endothelial cell migration and invasion, regulating their growth, survival and differentiation and they serve as receptors for a variety of extracellular matrix proteins including vitronectin, fibronectin, fibrinogen and osteopontin. They are involved in many biological processes such as angiogenesis, thrombosis, inflammation, osteoporosis and cancer playing a key role in many severe human diseases [7-9]. Up until now, $18 \alpha$ and $8 \beta$ subunits have been identified: they form 24 heterodimers, each with distinct ligand binding properties. 
Figure 1. Tripeptide Arg-Gly-Asp.

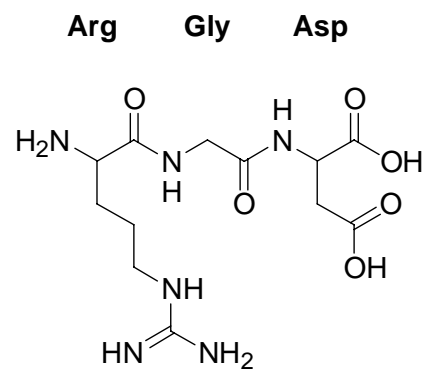

Among the integrin superfamily, $\alpha_{\mathrm{v}} \beta_{3}$ and $\alpha_{5} \beta_{1}$ integrins, targeted by the RGD sequence, play a pivotal role in the formation of new blood vessels in tissues (angiogenesis). They are overexpressed on activated endothelial cells during physiological and pathological angiogenesis [10]. Since $\alpha_{\mathrm{v}} \beta_{3^{-}}$ integrin is expressed on tumor cells of various types (melanoma, glioblastoma, ovarian and breast cancer) where it is involved in the processes that govern metastasis, it represents an attractive target for cancer therapy and has stimulated ongoing research to define high affinity ligands [11-12]. RGDcontaining integrin ligands have a large number of medical applications ranging from noninvasive visualization of integrin expression in vivo, to the synthesis of functionalized biomaterials.

This review will be divided into two different sections and cover the literature up until November 2009. The first section will discuss the synthesis of pseudopeptides containing the aforementioned tripeptide, whereas the second part will be focused on the introduction of the RGD sequence into polymers and biomaterials. The greater number of reported examples will be based on CuAAC chemistry, though some interesting applications of alternative click transformations will be illustrated.

\section{Functionalized Pseudopeptides}

The introduction of the RGD sequence in appropriately functionalized pseudopeptide structures allows the targeting of specific overexpressing-integrin cells, transferring to the biological system the peculiar characteristics of the synthesized peptides.

An important application which has recently received increasing interest is the preparation of probes for noninvasive visualization of the $\alpha_{\mathrm{V}} \beta_{3}$-integrin expression status. Various imaging modalities are available, ranging from nuclear imaging (SPECT: single electron emission computed tomography, PET: positron emission tomography), over magnetic resonance (MRI: magnetic resonance imaging), to optical methods dyes (FMT: fluorescent mediated tomography). All these methods require an integrin targeting probe conjugated to a suitable signal unit, that is, a radionuclide, a contrast agent or a fluorescent dye [13].

As the following examples will show, the click chemistry approach for the preparation of pseudopeptide compounds, both used as biological probes and substitutes of natural peptides, allows the synthesis of large biological molecules using mild reaction conditions. Often the protection of delicate functional groups is not required and a simple purification step affords the desired biomolecules, in a suitable state for biological assays. 


\subsection{Radiohalogenated compounds $\left({ }^{18}\right.$ F-labelled compounds)}

Chemoselective oxime ligation, a selective reaction of an aldehyde with a hydroxyl amino group (see Scheme 2), has been proposed by Kessler and co-workers as a versatile tool for the introduction of a radio marker in peptides. The major advances of this methodology are the high chemoselectivity, the use of unprotected aminooxy precursors and the fact that the coupling with the carbonyl component can be performed in aqueous media.

Scheme 2. Chemoselective oxime ligation.

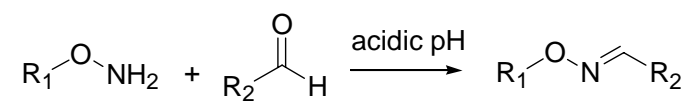

Kessler described in detail the solid phase synthesis of peptides containing the cyclo-RGDfE sequence, appropriately linked to the aminooxy functionality required for the chemoselective oxime ligation. The subsequent coupling of these peptides with $p$-trimethylstannylbenzaldehyde afforded useful precursors for radioiodostannylation (Figure 2) [14]. The advantages of this methodology were then used by the same authors for the efficient synthesis of ${ }^{18} \mathrm{~F}$-labelled peptides [15]. ${ }^{18} \mathrm{~F}$ is an important source of positrons and it represents the ideal radionuclide for PET. ${ }^{18} \mathrm{~F}$-labelled target specific peptides are widely used as in vivo imaging agents but, because of the physical half-life of ${ }^{18} \mathrm{~F}$ (109.7 $\mathrm{min}$ ), it is very important to have in hand a synthetic method which allows the clean and rapid introduction of the radio label. 4- $\left[{ }^{18} \mathrm{~F}\right]$ Fluorobenzaldehyde $\left(\left[{ }^{18} \mathrm{~F}\right] \mathrm{FB}-\mathrm{CHO}\right)$ was prepared from the 4formyl- $N, N, N$-trimethylanilium precursor via direct no-carrier-added ${ }^{18}$ F-fluorination and, after purification, it was coupled to aminooxy-functionalized peptides with an overall radiochemical yield (decay corrected) of up to $40 \%$ (Scheme 3).

The chemoselective oxime ligation has been applied for the preparation of ${ }^{18} \mathrm{~F}$-labelled multimeric cyclo-RGDfE peptides, as depicted in Figure 2. There is a clear positive effect for multivalency: the affinity of 1 vs. 2 vs. 3 for the $\alpha_{v} \beta_{3}$-integrin increased by around a factor of 10 with each multimerization step leading to improved tumor accumulation.

Peptide 2, as a representative RGD analogue, was used for extensive in vivo biodistribution studies showing favorable pharmacokinetics and high tumor-to-non-tumor ratios, thus demonstrating the suitability of these labelled peptides for PET applications.

However, using 4-[ $\left[{ }^{18} \mathrm{~F}\right]$-fluorobenzaldehyde as the prosthetic group invariably increases ligand lipophilicity, which often leads to a deterioration in tracer pharmacokinetics. To prevent this effect in two recent publications cited the use of the well accepted and easily available 2- $\left[{ }^{18} \mathrm{~F}\right]$-fluoro-2deoxyglucose $\left(\left[{ }^{18} \mathrm{~F}\right] \mathrm{FDG}\right)$ PET tracer as a prosthetic group for the synthesis of ${ }^{18} \mathrm{~F}$-labelled peptides. Gambhir and co-workers synthesized two labelled RGD-containing peptides $\mathbf{4}$ and $\mathbf{5}$ via chemoselective oxime ligation [16]. At $100{ }^{\circ} \mathrm{C}$, FDG exists in a dynamic equilibrium between its cyclic and linear form. This second form contains the aldehyde functionality that can react with the aminooxy functionality of a suitably modified peptide. Linear- and cyclo-aminooxy-RGD peptides were reacted at $100{ }^{\circ} \mathrm{C}$ with FDG in the presence of $0.4 \%$ TFA to give the corresponding conjugates in a 27.5 and $41 \%$ radiochemical yield (decay corrected) respectively (Scheme 4). High-contrast PET images with 
relatively moderate tumor uptake were observed for the two compounds as PET probes in xenograft models expressing $\alpha_{\mathrm{v}} \beta_{3}$ integrin.

Figure 2. Structures of $\left[{ }^{18} \mathrm{~F}\right] \mathrm{FBOA}$ labelled cyclo-RGD peptides.

$x$<smiles>NC(=O)CON=Cc1ccccc1</smiles><smiles>CC(CC(=O)O)C(=O)NC(=O)O</smiles>

$\mathrm{X}=\mathrm{SnMe}_{3}$ or ${ }^{18} \mathrm{~F}$

$\mathrm{X}={ }^{18} \mathrm{~F}$ : cyclo(RGDfE)HEG-Dpr-[ $\left.{ }^{18} \mathrm{~F}\right] \mathrm{FBOA} 1$

${ }^{18} \mathrm{~F}$

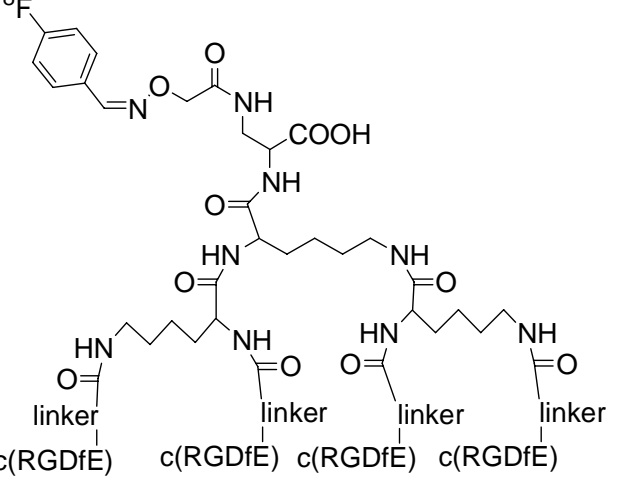

$\left((\text { cyclo(RGDfE)HEG })_{2}-\mathrm{K}\right)_{2}$-Dpr-[ $\left.{ }^{18} \mathrm{~F}\right] \mathrm{FBOA} 3$

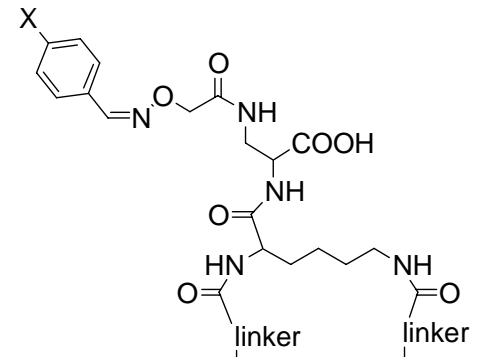

c(RGDfE) $\quad c$ (RGDFE)

$\mathrm{X}={ }^{18} \mathrm{~F}:(\mathrm{cyclo}(\mathrm{RGDfE}) \mathrm{HEG})_{2}-\mathrm{K}-\mathrm{Dpr}-\left[{ }^{18} \mathrm{~F}\right] \mathrm{FBOA} 2$

linker HEG:

$\mathrm{H}_{2} \mathrm{~N} \curvearrowright \mathrm{O} \sim \mathrm{O} \sim \mathrm{O} \sim \mathrm{O} \sim \mathrm{O}_{\mathrm{O}} \widehat{C O O H}_{\mathrm{COH}}$

Scheme 3. Radiosynthesis of $\left[{ }^{18} \mathrm{~F}\right] \mathrm{FB}-\mathrm{CHO}$ followed by coupling to aminooxyfunctionalized peptides via oxime formation.

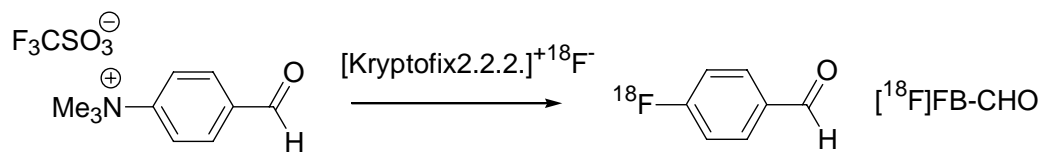

$\left[{ }^{18} \mathrm{~F}\right] \mathrm{FBOA}=\mathrm{N}-\left(4-\left[{ }^{18} \mathrm{~F}\right] \mathrm{fluorobenzylidene}\right)$ oxime

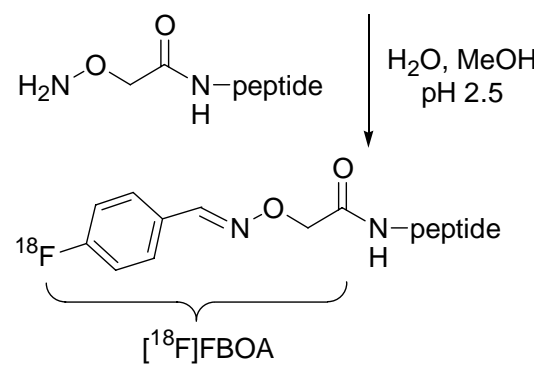

Analogously, Wester and co-workers described the direct conjugation of an aminooxyfunctionalized RGD peptide cyclo(RGDfK)-ONH${ }_{2}$ with no-carrier-added [ $\left.{ }^{18} \mathrm{~F}\right] \mathrm{FDG}$ [17]. No-carrieradded $\left[{ }^{18} \mathrm{~F}\right]$ FDG was obtained by HPLC separation from excess glucose of the $\left[{ }^{18} \mathrm{~F}\right] \mathrm{FDGTUM}$ 
prepared from routine in-house synthesis at the Technische Universität München (TUM). The corresponding conjugate was obtained in yields of up to 93\% (decay corrected) and activities up to $37 \mathrm{MBq}$ (Scheme 5).

Scheme 4 . Synthesis of $\mathbf{4}$ and $\mathbf{5}$ by chemoselective oxime ligation.

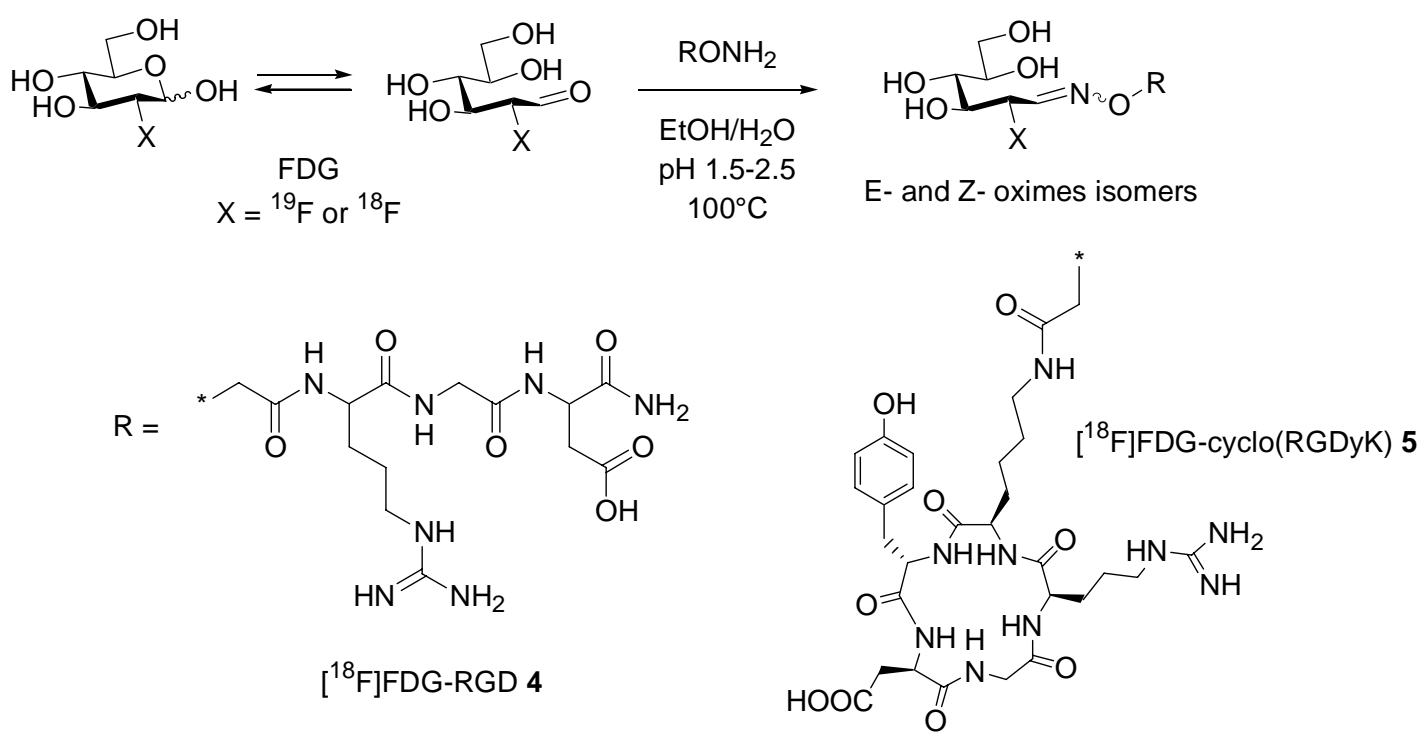

Scheme 5. Synthesis of $\left[{ }^{18} \mathrm{~F}\right]$ FDG-RGD 6 by chemoselective oxime ligation.
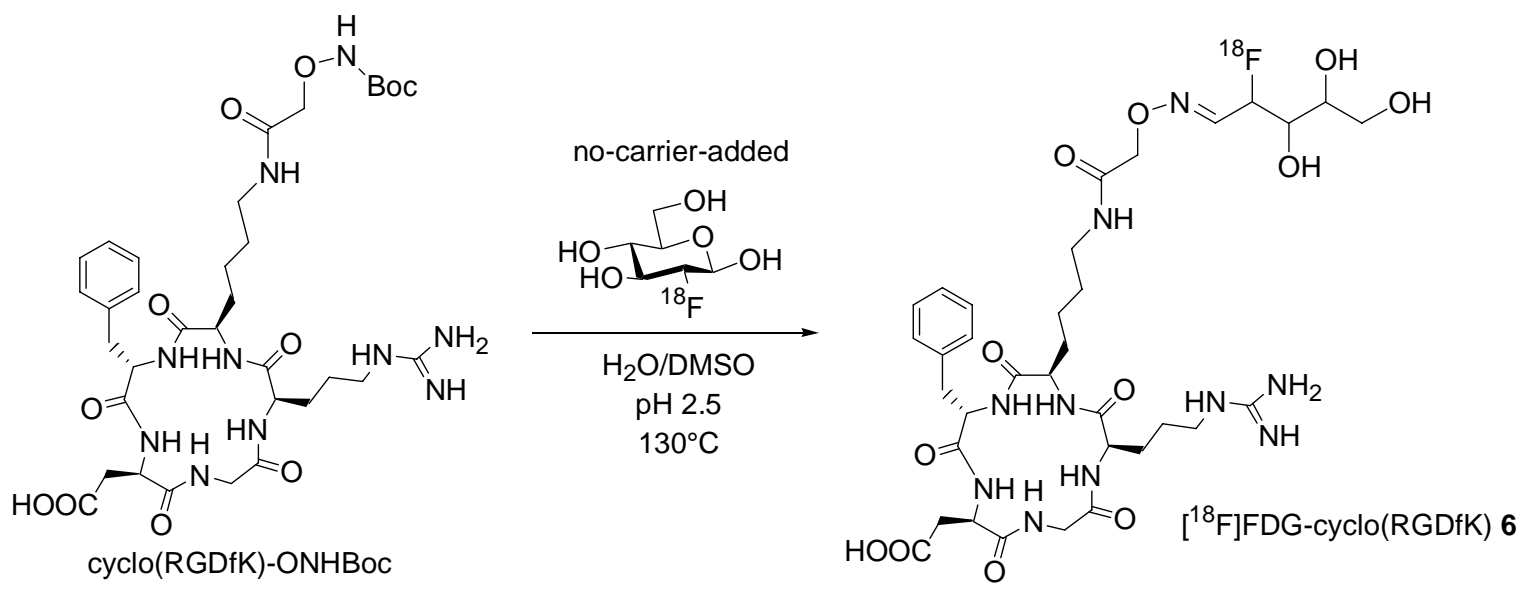

In a preliminary in vivo biodistribution study in M21 melanoma-bearing nude mice, $\left[{ }^{18} \mathrm{~F}\right] \mathrm{FDG}$-RGD showed increased tumor accumulation compared to $\left[{ }^{18} \mathrm{~F}\right]$-galacto-RGD, the only integrin-ligand presently in clinical studies [13].

A different synthetic approach for the introduction of the prosthetic group was employed by the group of Chen. In this case, the labelling reaction is based on the $\mathrm{Cu}(\mathrm{I})$-catalyzed Huisgen 1,3-dipolar cycloaddition. The authors prepared a dimeric-cyclo-(RGDyK) peptide labelled with their newly developed ${ }^{18} \mathrm{~F}$ synthon as represented in Scheme 6 [18]. Nucleophilic fluorination of the $p$ toluenesulfonic alkyne provided ${ }^{18} \mathrm{~F}$-alkyne 7 in high yield (65\% nondecay-corrected yield) and under mild conditions. The presence of the triethylene glycol linker is necessary to reduce volatility and to obtain water solubility. The azide moiety was introduced on the biomolecule by condensing the glutamate amino group of the cyclo-(RGDyK) dimer with an opportune azide-activated ester. The 1,3- 
dipolar cycloaddition is an extremely useful method for the introduction of the ${ }^{18} \mathrm{~F}$ synthon, considering both the short reaction time (45 minutes including HPLC purification) and the high labelling yield (52 $\pm 8 \%$ nondecay-corrected yield). The ${ }^{18}$ F-labelled peptide 8 was subjected to microPET studies in murine xenograft models showing good tumor uptake and relatively good metabolic stability as well as favourable in vivo pharmacokinetic.

Scheme 6. Radiosynthesis of ${ }^{18}$ F-fluoro-(triethylene glycol)-triazole-E[c(RGDyK) $]_{2} \mathbf{8}$.
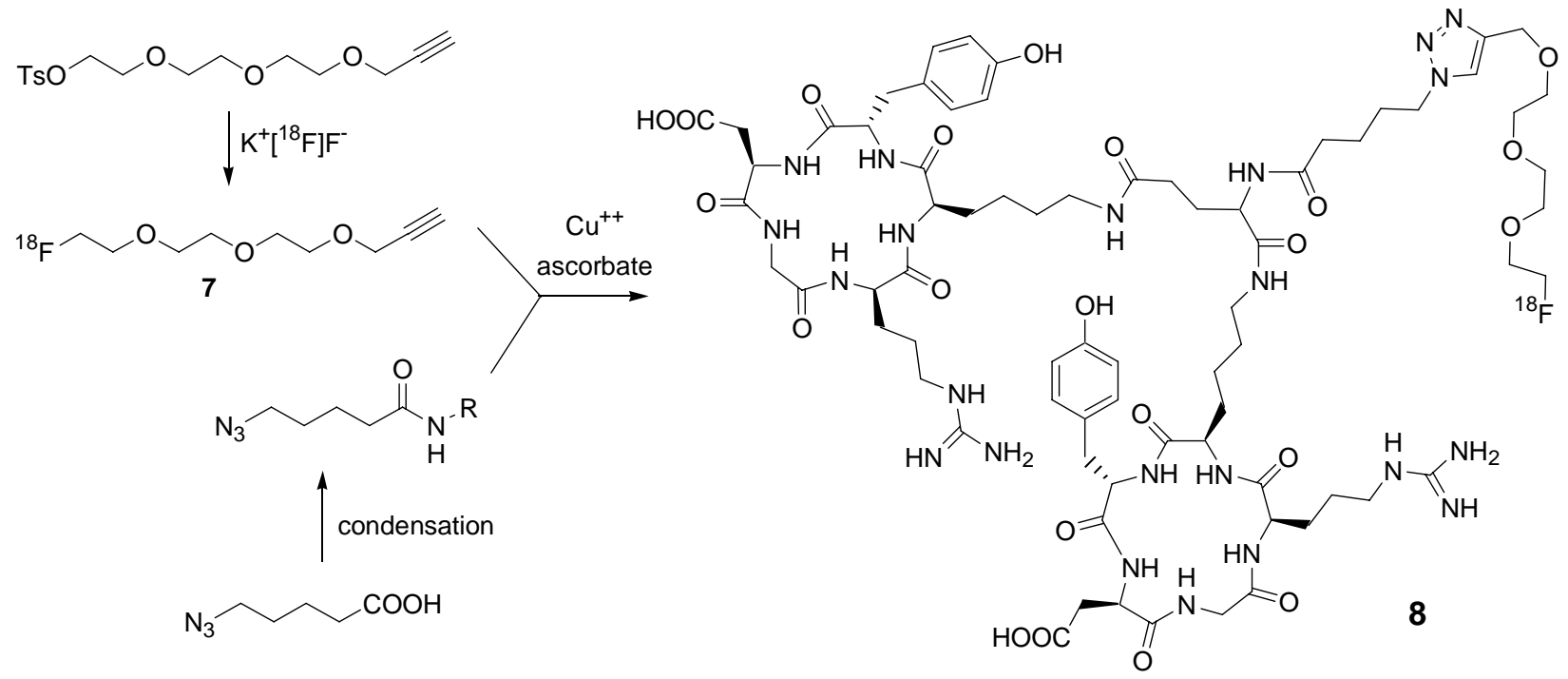

\subsection{Radiometalated compounds}

A different approach for potential tumor targeting and imaging involves the use of bifunctional radiometal chelating systems such DOTA (1,4,7,10-tetraazacyclododecane-1,4,7,10-tetraacetic acid) or DTPA (diethylenetriaminepentaacetic acid) (Figure 3).

Figure 3. Bifunctional radiometal chelating systems.<smiles>O=C(O)CN(CCN(CC(=O)O)CC(=O)O)CC(=O)O</smiles><smiles></smiles>

Some $\alpha_{v} \beta_{3}$-integrin ligands have been radiometalated using chelators of this type. One example comes from the group of Liskamp where a series of multivalent cyclo-RGDfK peptides were conjugated to DOTA via 1,3-dipolar cycloaddition [19]. A convergent synthesis of aminoacid-based dendrimers was employed for the preparation of DOTA conjugated dendrimeric alkynes. They were subsequently coupled via a microwave assisted 1,3-dipolar cycloaddition to azido cyclo-RGDfK peptides. The representative structure of the tetravalent derivative $\mathbf{9}$ is shown in Figure 4 . It should be emphasized that the carboxylic functionality of the DOTA-moiety needed to be protected by $t$-butyl 
groups during the cycloaddition step to avoid premature and irreversible sequestering of $\mathrm{Cu}^{2+}$ ions. Chelated copper (II) results in a lower efficiency of the redox couple and it hampers the radiolabeling of DOTA-moiety with trivalent radiometals such as ${ }^{111} \mathrm{In},{ }^{90} \mathrm{Yt}$ or ${ }^{177} \mathrm{Lu}$. Thus, after the click reaction an additional step of deprotection is required.

Figure 4. DOTA conjugated tetravalent cyclo(RGDfK) peptide dendrimer $\mathbf{9}$.
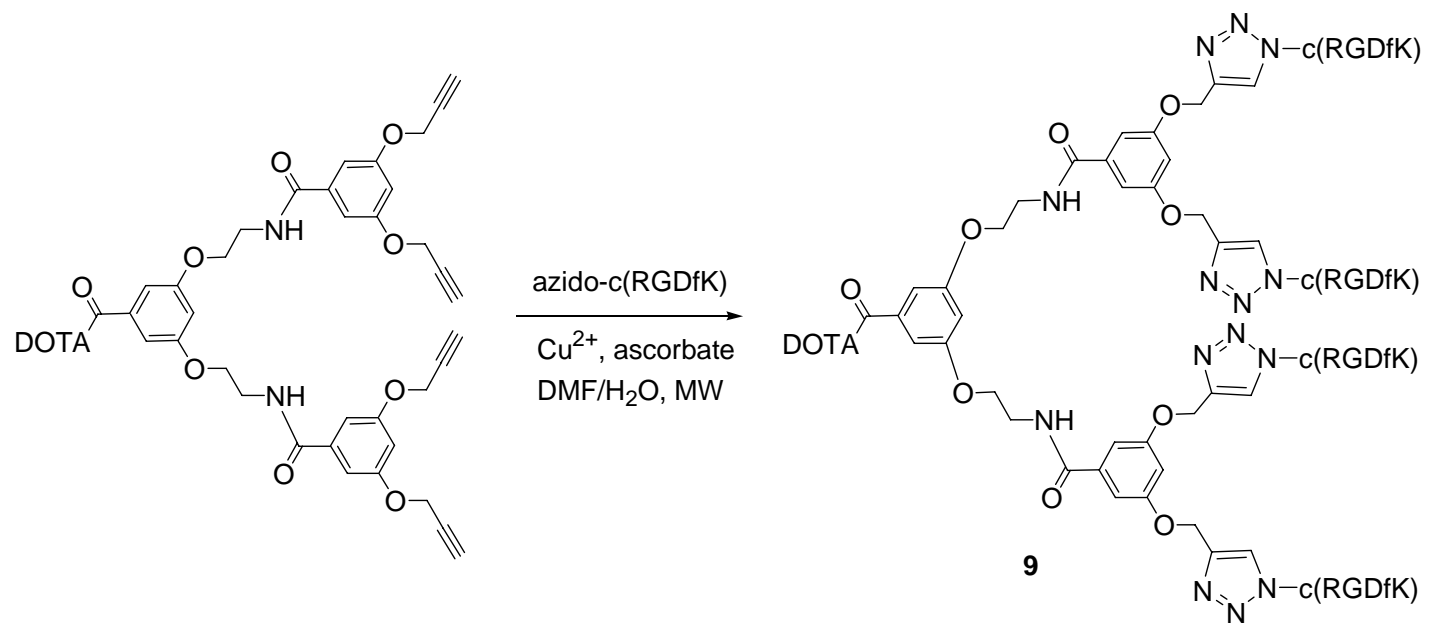

All the synthesized analogs were radiolabelled with ${ }^{111}$ In to evaluate the in vitro receptor binding characteristics and in vivo tumor targeting properties. IC $_{50}$ measurements showed the enhanced affinity effect of multivalency, while biodistribution studies showed that the tetrameric RGD-dendrimer possessed better tumor targeting properties than its dimeric and monomeric congeners.

Copper-independent strategies have been developed for in vivo use. Rutjes and co-workers recently described how easily accessible trifluoromethyl-substituted oxanorbornadiene derivatives react with azides in a tandem [3+2] cycloaddition-retro-Diels-Alder reaction (crDA) to form stable triazolelinked compounds. As this reaction can be performed in aqueous media, at ambient temperature, and in absence of copper, it represents a valid alternative to the classical Huisgen azide-alkyne cycloaddition. Moreover, oxanorbornadiene derivatives possess an increased reactivity towards azides compared to the corresponding electron-deficient alkynes. Although both double bonds can react, the 1,4,5substituted triazoles were predominantly formed (Path a, Scheme 7). As a first example of the application as a new bioconjugation method for the functionalization of peptides and proteins, an azide-functionalized hexapeptide (GGRGDG) was conjugated to a PEG functionalized oxanorbornadiene [20].

Scheme 7. Reaction pathways for the metal-free triazole formation.

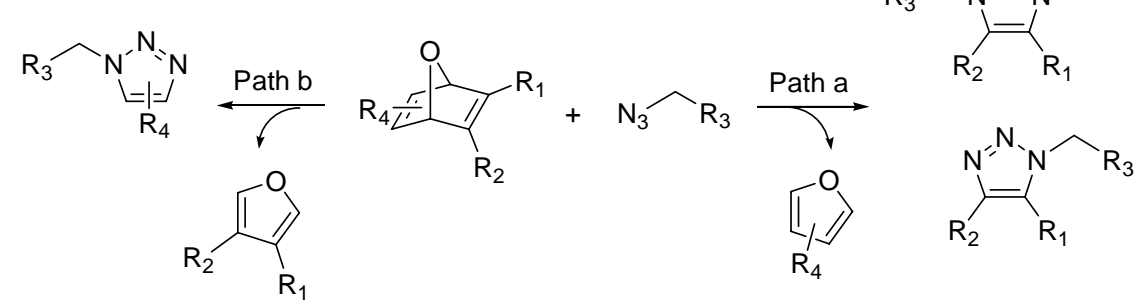


The absence of copper during the conjugation step is particularly useful for the introduction of ligands for radiolabelling such as DTPA. A DTPA radiolabel was conjugated to a $N$ - $\delta$-azidocyclo(RGDfX) 10 via oxanorbornadiene derivatives (Scheme 8) [21]. Preliminary biological evaluation showed high affinity for integrin $\alpha_{\mathrm{v}} \beta_{3}\left(\mathrm{IC}_{50}=192 \mathrm{nM}\right)$ and favourable pharmacokinetics.

Scheme 8. Tandem crDA reaction of c(RGDfX) and methyloxanorbornadiene-DTPA.
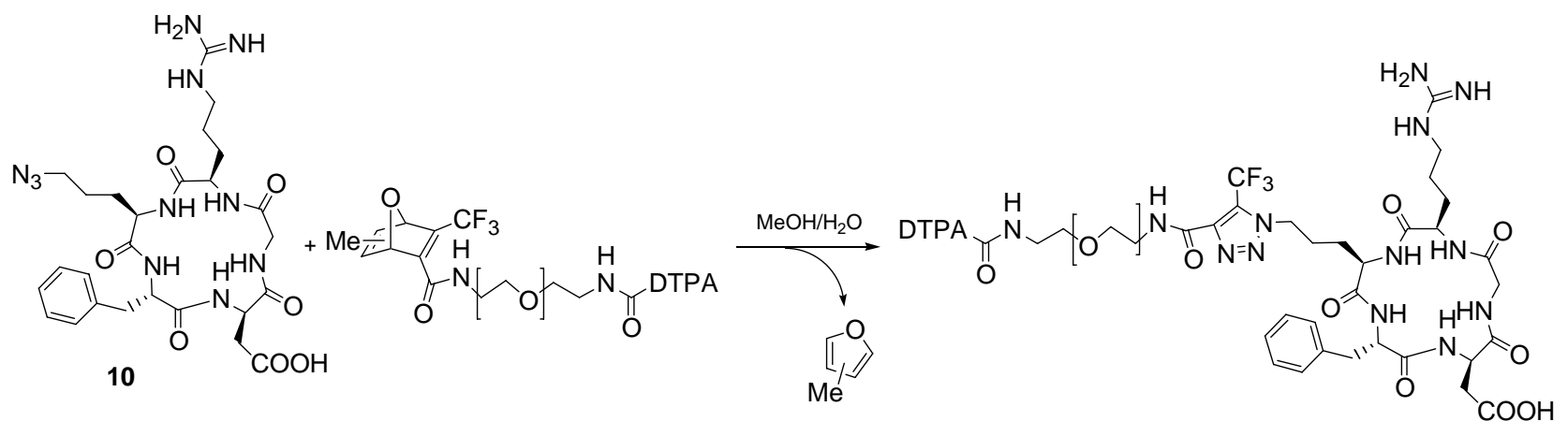

The effects of the concentration of the reactants, temperature, $\mathrm{pH}$ and reaction environment on the kinetics of the reaction were then evaluated in order to optimize the synthesis. The biodistribution of the labelled compound in mice $\left({ }^{111} \mathrm{In}\right.$ was selected because of its long half-life: $67.2 \mathrm{~h}$ and its stability in the DTPA chelate) was determined, confirming specific accumulation of the conjugate in $\alpha_{v} \beta_{3^{-}}$ integrin-expressing tissues [22].

\subsection{Fluorescent compounds}

Another important method used for in vivo imaging is the introduction of fluorescent dyes. Manzoni and co-workers have recently reported the synthesis of two cycloRGD peptide-fluorescein conjugates 11 and 12 that could be used as in vivo markers for $\alpha_{v} \beta_{3}$-integrin expression in human cells [23]. The green fluorescent dye fluorescein is widely used as a probe due to its known safety profile. Two different synthetic strategies were used by the authors for the conjugation with fluorescent probes of cyclic RGD compounds containing the conformationally constrained homoSer-Pro dipeptide unit. The first strategy involved the functionalization of the RGD cyclopeptide with a short poly(ethylene glycol) spacer armed with a terminal amine group and able to form a stable thiourea bridge with commercially available fluoresceine isothiocyanate, through an efficient click carbonyl chemistry reaction. The second approach required the preparation of a fluorescent derivative with a terminal triple bond that can be directly reacted with the azide group of the RGD cyclopeptide through the copper-catalyzed 1,3-dipolar cycloaddition (Scheme 9).

After in vitro treatment, the fluorescent probe was detectable in a panel of cell lines highly expressing $\alpha_{\mathrm{v}} \beta_{3}$ integrin as endothelial cells (HUVEC) and several human cell lines derived from solid tumors. Moreover, the pattern of detected fluorescence also suggested that both compounds were dynamically internalized by cells.

In another recent example, Baker and co-workers described the synthesis and evaluation of in vitro biological activity of poly(amidoamine) (PAMAM) dendrons with c(RGDyK) peptides on their surfaces. A unique alkyne group present at the dendron focal point was reacted with an azide- 
functionalized dye [derivatized Alexa Fluor (AF) 488] via 1,3-dipolar cycloaddition thus generating a fluorescent high avidity binding agent (Figure 5) [24]. AF488 was chosen as the fluorescent label for the detection of conjugates as it is brighter than fluorescein and more resistant to photobleaching. The specific binding of the conjugate to $\alpha_{\mathrm{v}} \beta_{3}$ integrin expressing HUVEC and U87MG cells was examined by flow cytometry. The alkyne functionalized dendron was also conjugated to biotin, to a second dyeconjugated dendron and to methotrexate, a therapeutic drug, using the appropriate azide-derivatized molecule.

Scheme 9. Synthesis of cyclo-RGD peptide-fluorescein conjugates 11 and 12.
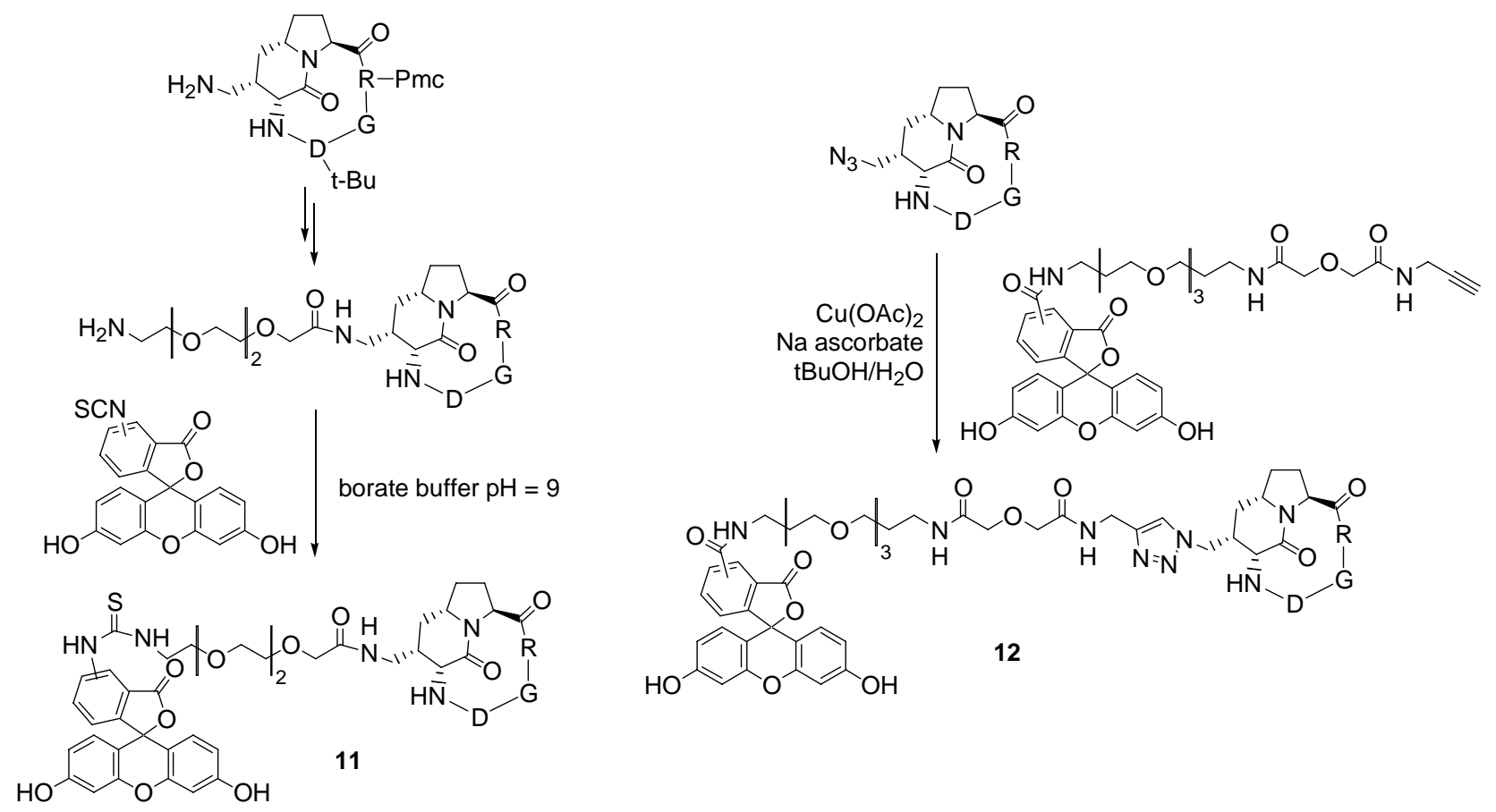

\subsection{Peptide analogues}

Click chemistry has been recently employed for the preparation of peptide analogues after the application of the 1,2,3-triazole moiety was reported as peptide bond isosteres. A new family of cyclopeptide analogues cyclo[-Arg-Gly-Asp- $\psi$ (triazole)-Gly-Xaa-] 13 in which an amide bond was replaced by the 1,2,3-triazole moiety was synthesized by Pan and co-workers [25]. The synthetic strategy described in this paper represents the first example of the application of the [3+2] Huisgen cycloaddition in solution cyclization and synthesis of integrin binding peptides as outlined in Scheme 10.

The linear peptide analogue ( $\mathrm{N}_{3}$-Gly-Gly-Arg(Pbf)-Gly-Asp-propargyl) was synthesized by standard solid-phase peptide synthesis strategy on resin. The cyclization was performed in solution and a variety of reaction conditions were evaluated to optimize the process. The best results were obtained employing 1/3 mol per cent of $\mathrm{CuBr} / \mathrm{DBU}$ as the catalyst and dichloromethane as the solvent. The cytotoxic activity of all the cyclopetide analogues was evaluated using MTT method, showing, in some cases, activities comparable to cRGDfK that was employed as the positive control. 
Figure 5. Structure of the fluorescent dendron conjugate AF-G3(COOH $)_{12}(\mathrm{RGD})_{4}$.

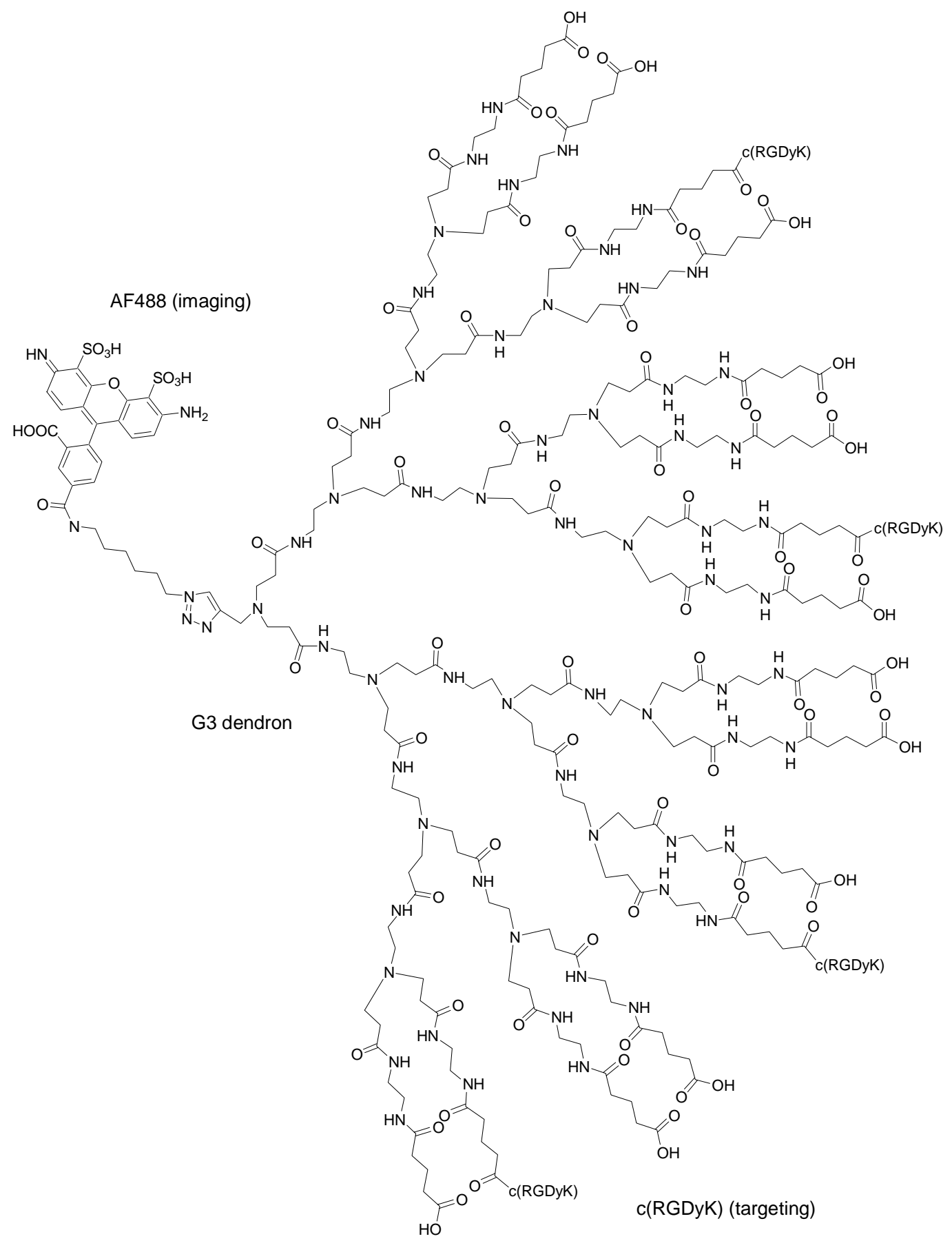

In a second example, Finn and co-workers described the selective production of large cyclic dimers from resin-tethered peptides containing azide and alkyne residues. The 11-mer and 19-mer RGDcontaining peptides shown in Scheme 11 contain a sequence taken from adenovirus serotype that binds several $\alpha_{\mathrm{v}}$ integrins. Head to tail macrocyclization was performed via 1,3-dipolar cycloaddition using 0.5 equivalent of the $\mathrm{Cu}(\mathrm{I})$ catalyst (Scheme 11) [26]. The properties of the resin and the solvent were found to be crucial for the selectivity of the process (cyclic dimers vs. cyclic monomers). The process resulted independent of the peptide sequence but the need for a long and flexible chain was confirmed by the fact that peptides shorter than hexamers were predominantly converted to cyclic monomers [27]. 
Scheme 10. Synthesis of cyclopeptide analogues cyclo[-Arg-Gly-Asp- $\psi($ triazole)-Gly-Xaa-] 13.

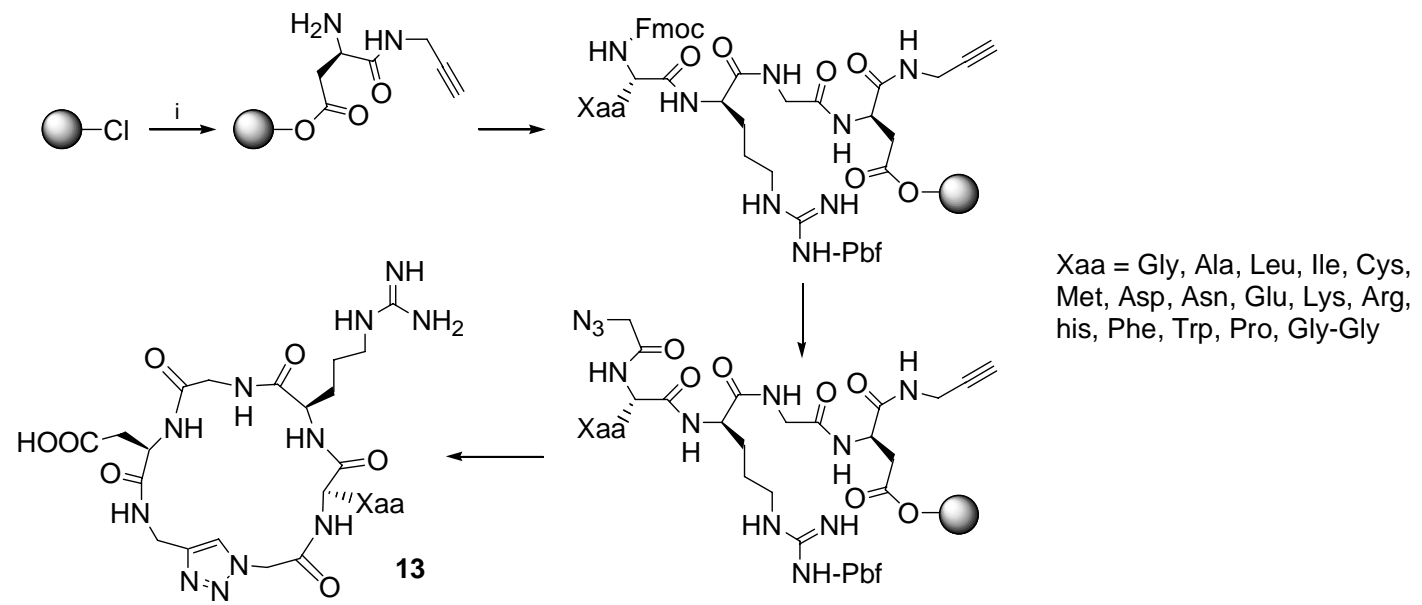

Scheme 11. On resin cyclodimerization.

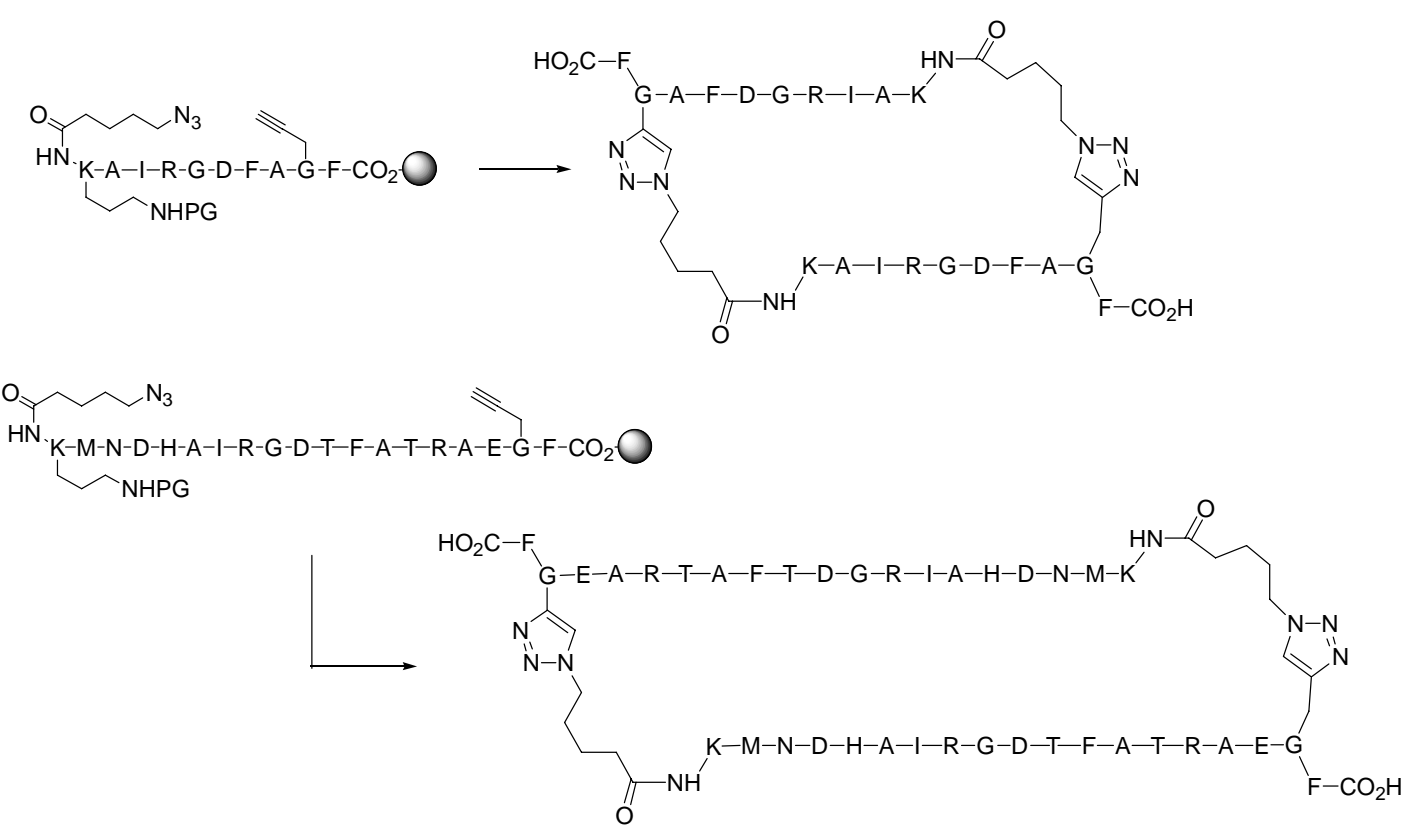

\subsection{Glycosylated peptides}

The preparation of a glycosylated RGD derivative in order to evaluate the value of a triazole moiety as an amide isostere in terms of electronic properties and atom placement has been recently described by Rutjes and co-workers [28]. The authors showed that 1-azido sugars and acetylene-modified amino acids readily undergo [3+2] cycloaddition to form triazole isosters of glycoamino acids (Scheme 12). The obtained glycosylated amino acid was used as a building block in the following solid phase synthesis of the cyclic peptide c(RGDy- ${ }^{N}$ TGA) 14.

The presence of the triazole analogue increased the chemical stability of the compound with respect to the amide linked $\mathrm{c}(\mathrm{RGDy}-[N-1-\beta$-gluco-Asn]) 15. Moreover, biodistribution studies indicated that the glycosylated peptide showed improved pharmacological properties compared to more hydrophobic/lipophilic peptides such as c(RGDyV). 
Scheme 12. Synthesis of glycosylated amino acid and c(RGDy- ${ }^{N}$ TGA) 14.

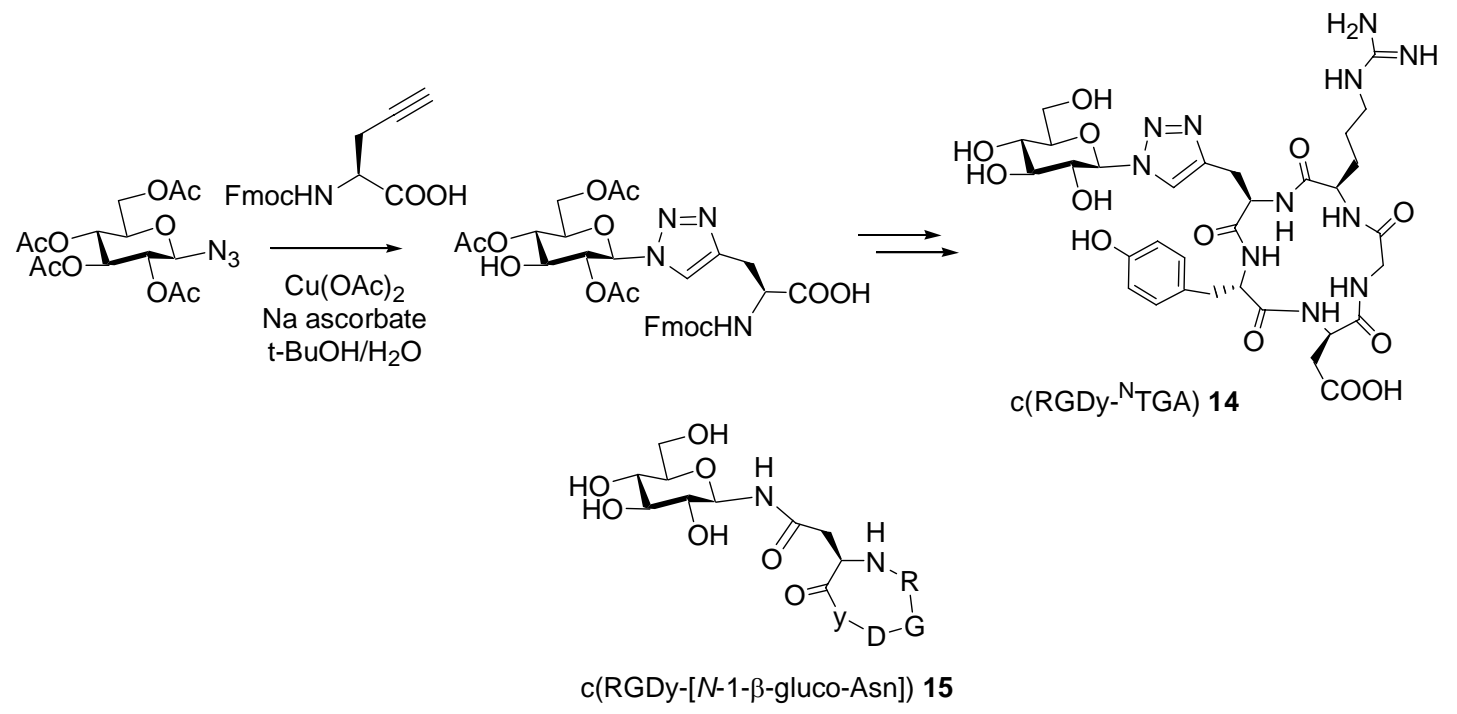

\section{Biomaterials}

During the last few years the use of materials such as polymers in conjugation with active biological molecules has increasing success, with consequent demand of more and more defined structures. The growth of click chemistry has enriched and simplified the strategies of conjugation between materials and organic molecules, due to the ready availability of active building blocks, the possibility of performing the reactions at room temperature in aqueous media and almost complete conversions [29]. This part of the review will be focused on the linkage between materials and systems containing the tripeptide RGD, highlighting how the polymers may gain useful applications in biomedical areas.

As first examples, hydrogels have been widely studied and utilized as biomaterials due to the high hydration level and the three dimensional scaffold structure, which give the similarities to the native extracellular matrix. Natural gelatin and collagen belong to this class of materials, but their use has been decreased because of the potential risk of infective diseases. Poly(ethylene glycol) (PEG), a hydrophilic polymer able to absorb large amounts of water and showing low immunogenicity represents a good substitute. Yang and co-workers prepared biodegradable PEG-peptide hydrogels containing the RGD sequence as potential cell delivery vehicles [30]. A stable triazole-based linkage between the polymer scaffold and RGD peptide was created by copper-mediated cycloaddition. Tetrahydroxy terminated 4-arm PEG was functionalized with 4-pentynoic acid, whereas a series of decapeptides were prepared by classical Fmoc-based solid phase peptide synthesis and then functionalized with 6-azidohexanoic acid. The subsequent CuAAC and gelation yielded the expected PEG-peptide hydrogels (Scheme 13). Cell attachment and proliferation experiments were performed to demonstrate the potential of PEG-RGD peptide hydrogels as useful biodegradable supports. Thanks to the integrin receptor-mediated extracellular signal, the cells on the hydrogels formed using a large amount of RGD (2.7 or $5.4 \mathrm{mM}$ in the precursor solution) were well attached and spread well with healthy morphology thus making these materials promising carriers for cell delivery. 
Scheme 13. Synthesis of PEG-peptide hydrogel.

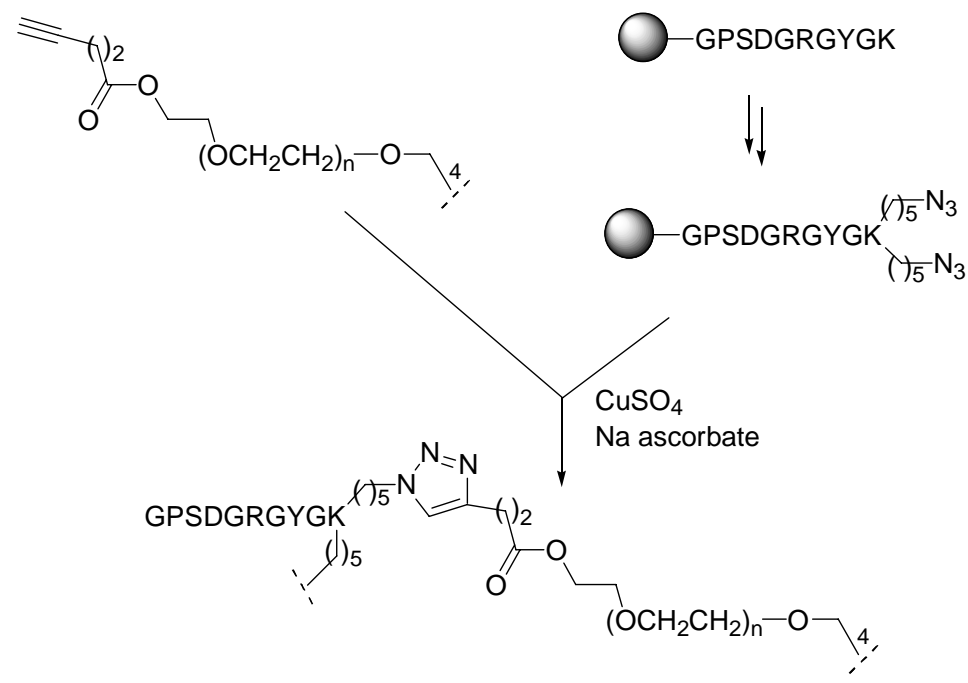

Analogously, Jabbari and co-workers took advantage of the combination of RGD peptides and hydrogel substrates to develop engineered scaffolds. The aim of the work was the grafting of the RGD peptide and BMP-2 (bone morphogenetic protein-2) peptide onto biodegradable inert hydrogels, and their use as scaffolds for the regeneration of skeletal tissues through osteogenic differentiation and mineralization of bone marrow stromal (BMS) cells [31]. The hydrogel scaffold, shown in Figure 6, was prepared by the cross-linking of macromer poly(lactide-ethylene-oxide-fumarate) (PLEOF) with acrylamide-termined GRGD and propargyl acrylate. Thereafter the PEGylated BMP peptide functionalized with 4-carboxybenzenesulfonazide was grafted onto the RGD hydrogel via coppermediated cycloaddition in ambient conditions. Due to the fact that all the reaction by-products had a high solubility in aqueous solution, the purification of the gel was performed successfully by simple washing. The density on the hydrogel surface of both peptides was good, as well as the increased extent of mineralization of the BMS cell, obtained by the synergistic action of RGD and BMP peptides.

Figure 6. Schematic structures of RGD hydrogel and functionalized BMO peptide.

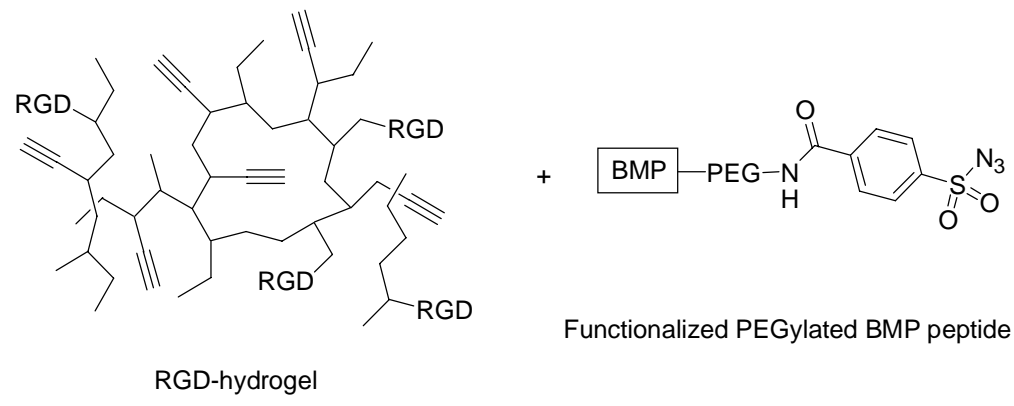

Click chemistry reactions have been largely used also for the functionalization of self-assembled monolayers (SAMs). A SAM is an organized layer of amphiphilic molecules formed on a variety of inert surfaces, including glass, silicon, gold diamond and amorphous carbon. The amphiphilic layer terminates with a head group showing special affinity for a substrate. Due to the capacity of 
controlling surface properties, such as bioinertness or biomolecule presentation, SAMs have emerged as helpful tools in the study of biochemical interactions.

Following this concept, Hudalla and Murphy prepared SAMs formed from the mixed coordination of different alkanethiolates onto a gold-coated substrate. In particular the authors used azideterminated hexa(ethylene glycol) alkanethiolate and tri(ethylene glycol) alkanethiolate to prepare a SAM presenting groups to allow for a click chemistry conjugation. Immersion of the functionalized gold substrate into a solution containing the peptide Arg-Gly-Asp-Ser-Pro bearing a terminal alkyne moiety and the catalytic mixture $\mathrm{CuBr}$ and sodium ascorbate led rapidly and quantitatively to the chemoselective linkage of the peptide to SAM through the CuAAC reaction (Scheme 14). Terminal oligo(ethylene glycol) prevented nonspecific protein adsorption rendering bioinert the monolayer, however the presence of the RGD system allowed a selective adhesion and spreading of human mesenchymal stem cells, demonstrating how SAMs may be useful as active substrates for stem cell studies [32].

Scheme 14. Conjugation of the RGD system on SAM via CuAAC.
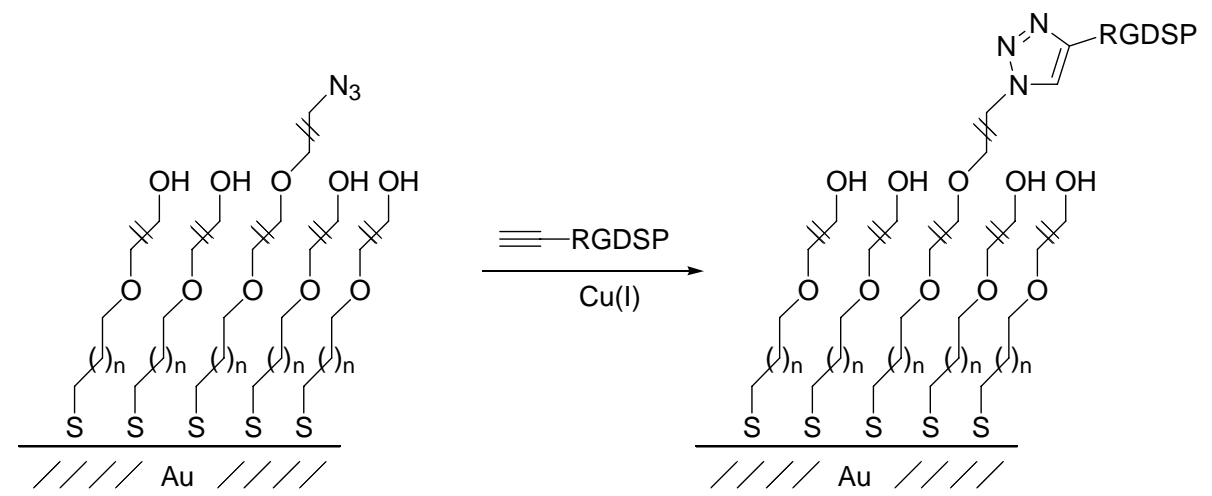

The RGD peptide was also introduced by Becker and co-workers onto SAM substrates by classical click alkyne-azide cycloaddition. The authors deposited n-octyldimethylchlorosilane onto silicon wafer and glass slide surfaces. A subsequent gradient ozone treatment produced selective terminal oxidation of the SAM which was then functionalized with a linker bearing a propargyl moiety. The RGD-containing peptide was covalently immobilized into the gradient substrate via copper-catalyzed triazole cycloaddition (Figure 7a). Smooth muscle cells were cultured on the layers and the number of adherent cells increased as a function of the position of gradient and hence of the increasing RGD density along the substrate, thus highlighting the ability of the SAM in modulating biofunctionalizations [33].

Luk and co-workers immobilized peptides onto alkanethiolate-based SAMs through an alternative substitution reaction, which can be considered click-like, due to the high chemoselectivity and irreversibility, easy purification and the use of water as the solvent. Terminal tri(ethylene glycol) groups of alkanethiol chains were functionalized with phenoxy squarate, which is able to couple covalently at $\mathrm{pH} 5.5$ with $\mathrm{N}$-terminus cysteine peptides selectively (Figure $7 \mathrm{~b}$ ). Peptides containing $\mathrm{C}$ terminus cysteine and internal cycteines did not react under the reported conditions. To evaluate successful immobilization of the peptides on the surface of the SAM, the RGD sequence was introduced as a specific cell-adhesion assay [34]. 
Figure 7. RGD-containing peptide immobilized onto silicon surface (a) and $N$-terminus cysteine immobilization on phenoxy-squarate SAM (b).

a.

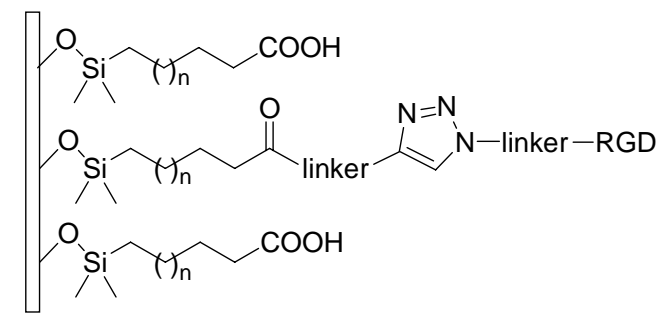

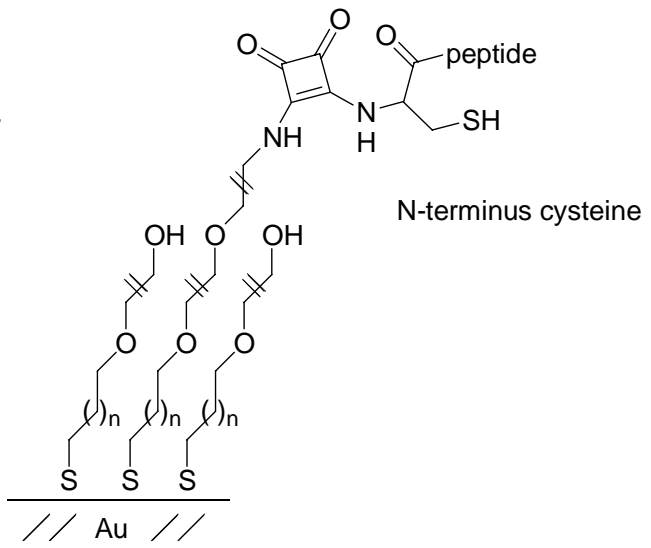

The previuos examples have demonstrated that the incorporation of the RGD sequence onto a polymer or a substrate is a quick method to produce innovative materials able to promote cell adhesion and growth. The following examples will extend to the usefulness of click chemistry for other types of functionalized materials and in particular the use of CuAAC as a successful way to introduce the wellrecognized adhesive RGD motif.

Emrick and co-workers prepared aliphatic polyesters with pendant acetylene moieties by tinmediated ring-opening polymerization. Subsequently, PEGs or oligopepdides containing the RGD motif were grafted through click CuAAC (Figure 8a) [35]. An alternative polymer based on welldefined poly(oligo(ethylene glycol) acrylate) (POEGA) was prepared by Lutz's group through atom transfer radical polymerization (ATRP). A bromine atom was present at the chain-ends, allowing a simple introduction of terminal azide moieties. Functionalized acetylenes, including the oligopeptide GGRGDG, were then anchored by efficient copper-catalyzed cycloaddition (Figure 8b) [36]. A further example is the peptide-functionalized multilayer prepared by Caruso and co-workers by the simple assembly technique known as layer-by-layer assembly. Each single PEG layer was covalently linked to the following through triazole moieties obtained by CuAAC. On the external surface of the modular PEG film free click groups were available for further cycloaddition reactions with appropriately decorated peptides, containing the RGD motif (Figure 8c) [37]. Niu, Wang and co-workers used M13 bacteriophage as a powerful nanoscale buiding block, thanks to the innate ability of this virus to organize into ordered films. The functionalization with spaced terminal alkynes of some amino groups on viral surface, known to be viable sites for chemical modifications, allowed the subsequent conjugation via click triazole synthesis of the RGD motif [38]. The last example reported here is the preparation of self-assembled polymeric nanoparticles, formed by the coupling of the hydrophobic poly(2-methyl-2-carboxytrimethylene carbonate-co-lactide) with a hydrophilic PEG functionalized with azide groups. The amphiphilic polymer obtained presented azide moieties on the surface for further modification with the alkyne-KGRGDS peptide by CuAAC (Figure 8d) [39]. Due to the presence of RGD-containing peptides, the abovementioned stable and efficient click biofunctionalized polymers showed a peculiar cell response, promoting specific cell adhesion and growth. 
Figure 8. RGD systems on functionalized polymers: aliphatic polyesters (a), poly(oligo(ethylene glycol) acrylate) (b), PEG multilayer (c) and polymeric nanoparticles (d).

a.<smiles>O=C(CCCCCO)OCCCCCC(=O)OCCOCCO</smiles>

c.

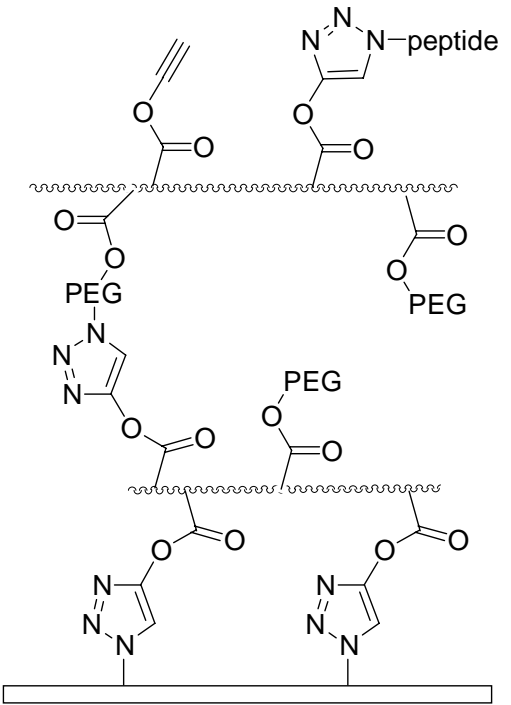

b.

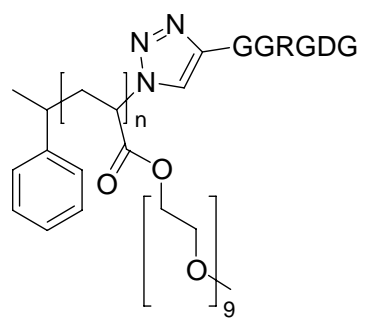

d.

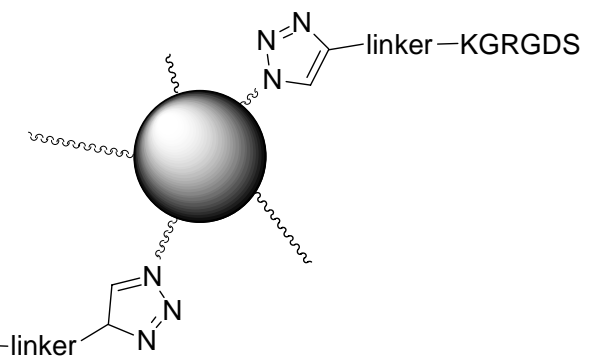

\section{Conclusions}

The classical advantages of click chemistry reactions (high yields, simple and mild reaction conditions, easy purification and use of water as the choice solvent) have allowed the conjugation of a number of different biomolecules, thus obtaining large and complex systems with tailored properties. Among these bioconjugate compounds, structures containing the highly recognized RGD tripeptide motif have obtained remarkable interest. The ability to bind selectively to transmembrane proteins on the cell surface and to involve cellular adhesion has allowed RGD to be a useful tool for the functionalization of (bio)materials and for the transfer of particular properties. Selective molecular probes carrying radiolabel atoms or fluorescent moieties have been prepared and used for the identification of specific target cells. In the biopolymer area, new materials able to act as cell attachment and proliferation points have opened the route to new and attractive possibilities of bioconjugation. Undoubtedly that the beneficial effects of click chemistry for the synthesis of biomolecules containing the RGD system will ensure the growth of this area in the future.

\section{References}

1. Kolb, H.C.; Finn, M.G.; Sharpless, K.B. Click chemistry: Diverse chemical function from a few good reactions. Angew. Chem. Int. Ed. 2001, 40, 2004-2021.

2. Bock, V.D.; Hiemstra, H.; van Maarseveen, J.H. CuI-catalyzed alkyne-azide "click" cycloadditions from a mechanistic and synthetic perspective. Eur. J. Org. Chem. 2006, 51-68. 
3. Tamkun, J.W.; DeSimone, D.W.; Fonda, D.; Patel, R.S.; Buck, C.; Horwitz, A.F.; Hynes, R.O. Structure of integrin, a glycoprotein involved in the transmembrane linkage between fibronectin and actin. Cell 1986, 46, 271-282.

4. Hynes, R.O. Integrins: Bidirectonal, allosteric signaling machines. Cell 2002, 110, 673-687.

5. Plow, E.F.; Haas, T.A.; Zhang, L.; Loftus, J.; Smith, J.S. Ligand binding to integrins. J. Chem. Biol. 2000, 275, 21785-21788.

6 Gottschalk, K.-E.; Kessler, H. The structures of integrins and integrin-ligand complexes: implications for drug design and signal transduction. Angew. Chem. Int. Ed. 2002, 41, 3767-3774.

7. Hynes, R.O. Integrins: Versatility, modulation, and signaling in cell adhesion. Cell 1992, 69, $11-25$.

8. Brooks, P.C.; Clark, R.A.; Cheresh, D.A. Requirement of vascular integrin $\alpha_{\mathrm{v}} \beta_{3}$ for angiogenesis. Science 1994, 264, 569-571.

9. Hynes, R.O. A reevaluation of integrins as regulators of angiogenesis. Nat. Med. 2002, 8, 918-921.

10. Rüegg, C.; Mariotti, A. Vascular integrins: pleiotropic adhesion and signaling molecules in vascular homeostasis and angiogenesis. Cell. Mol. Life Sci. 2003, 60, 1135-1137.

11. Pierschbacher, M.D.; Ruoslahti, E. Cell attachment activity of fibronectin can be duplicated by small synthetic fragments of the molecule. Nature 1984, 309, 30-33.

12. Meyer, A.; Auemheimer, J.; Modlinger, A.; Kessler, H. Targeting RGD recognizing proteins: Drug development biomaterial research, tumor imaging and targeting. Curr. Pharm. Des. 2006, 12, 2723-2747.

13. Schottelius, M.; Laufer, B.; Kessler, H.; Wester, H.-J. Ligands for mapping $\alpha_{\mathrm{v}} \beta_{3}$-integrin expression in vivo. Acc. Chem. Res. 2009, 42, 969-980.

14. Thumshirn, G.; Hersel, U.; Goodman, S.L.; Kessler, H. Multimeric cyclic RGD peptides as potential tools for tumor targeting: solid phase peptide synthesis and chemoselective oxime ligation. Chem. Eur. J. 2003, 9, 2717-2725;

15 Poethko, T.; Schottelius, M.; Thumshirn, G.; Hersel, U.; Herz, M.; Henriksen, G.; Kessler, H.; Schwaiger, M.; Wester, H.-J. Two-step methodology for high-yield routine radiohalogenation of peptides: ${ }^{18}$ F-Labeled RGD and octreotide analogs. J. Nucl. Med. 2004, 45, 892-902.

16. Namavari, M.; Cheng, Z.; Zhang, R.; De, A.; Levi, J.; Hoerner, J.K.; Yaghoubi, S.S.; Syiud, F.A.; Gambhir, S.S. A novel method for direct site-specific radiolabeling of peptides using $\left[{ }^{18} \mathrm{~F}\right] \mathrm{FDG}$. Bioconjugate Chem. 2009, 20, 432-436.

17. Hultsch, C.; Schottelius, M.; Auernheimer, J.; Alke, A.; Wester, H.-J. 18-Fluroglucosylation of peptides, exemplified on cyclo(RGDfK). Eur. J. Nucl. Mol. Imaging 2009, 36, 1469-1474.

18. Li, Z.-B.; Wu, Z.; Chen, K., Chin, F.T.; Chen, X. Click Chemistry for ${ }^{18}$ F-Labeling of RGD peptides and microPET imaging of tumor integrin $\alpha_{\mathrm{v}} \beta_{3}$ expression. Bioconjugate Chem. 2007, 18, 1987-1994.

19. Dijgraaf, I.; Rijnders, A.Y.; Soede, A.; Dechesne, A.C.; Wilma van Hess, G.; Brouwer, A.J.; Corstens, F.H.M.; Boerman, O.C.; Rijkers, D.T.S.; Liskamp, R.M.J. Synthesis of DOTAconjugated multivalent cyclic-RGD peptide dendrimers via 1,3-dipolar cycloaddition and their biological evaluation: implications for tumor targeting and tumor imaging purposes. Org. Biomol. Chem. 2007, 5, 935-944. 
20. Van Berkel, S.S.; Dirks, A.J.; Debets, M.F.; van Delft, F.L.; Cornelissen, J.J.L.M.; Nolte, R.J. M.; Rutjes, F.P.J.T. Metal-free triazole formation as a tool for bioconjugation. ChemBioChem 2007, 8, 1504-1508.

21. Van Berkel, S.S.; Dirks, A.J.; Meeuwissen, S.A.; Pingen, D.L.L.; Boerman, O.C.; Laverman, P.; van Delft, F.L.; Cornelissen, J.J.L.M.; Rutjes, F.P.J.T. Application of metal-free triazole formation in synthesis of cyclic RGD-DTPA conjugates. ChemBioChem 2008, 9, 1805-1815.

22. Laverman, P.; Meeuwissen, S.A.; van Berkel, S.S.; Oyen, W.J.G.; van Delft, F.L.; Rutjes, F.P.J.T.; Boerman, O.C. In-depth evaluation of the cycloaddition-retro-Diels-Alder reaction for in vivo targeting with [ ${ }^{111}$ In]-DTPA-RGD conjugates. Nucl. Med. Biol. 2009, 36, 749-757.

23. Arosio, D.; Manzoni, L; Araldi, E.M.V.; Caprini, A.; Monferini, E.; Scolastico, C. Functionalized cyclic RGD peptidomimetics: conjugable ligands for $\alpha_{\mathrm{v}} \beta_{3}$ receptor imaging. Bioconjugate Chem. 2009, 20, 1611-1617.

24. Mc Nerny, D.Q.; Kukowska-Latallo, J.F.; Mullen, D.G.; Wallace, J.M.; Desai, A.M., Shukla, R.; Huang, B.; Banaszak Holl, M.M.; Baker, J.R., Jr. RGD dendron bodies; synthetic avidity agents with defined and potentially interchangeable effector sites that can substitute for antibodies Bioconjugate Chem. 2009, 20, 1853-1859.

25. Liu, Y.; Zhang, L.; Wan, J.; Li, Y; Xu, Y.; Pan, Y. Design and synthesis of cyclo[-Arg-Gly-Asp$\psi$ (triazole)-Gly-Xaa-] peptide analogues by click chemistry. Tetrahedron 2008, 64, 10728-10734.

26. Punna, S.; Kuzelka, J.; Wang, Q.; Finn, M.G. Head-to-tail peptide cyclodimerization by coppercatalyzed azide-alkyne cycloaddition. Angew. Chem. Int. Ed. 2005, 44, 2215-2220.

27 Jagasia, R.; Holub, J.M.; Bollinger, M.; Kirshenbaum, K.; Finn, M.G. Peptide cyclization and cyclodimerization by $\mathrm{Cu}^{\mathrm{I}}$-mediated azide-alkyne cycloaddition. J. Org. Chem. 2009, 74, 2964-2974.

28. Kuijpers, B.H.M.; Groothuys, S.G.; Soede, A.C.; Laverman, P.; Boerman, O.C.; van Delft, F.L.; Rutjes, F.P.J.T. Preparation and evaluation of glycosylated Arginine-Glycine-Aspartate (RGD) derivatives for integrin targeting. Bioconjugate Chem. 2007, 18, 1847-1854.

29. van Dijk, M.; Rijkers, D.T.S.; Liskamp, R.M.J.; van Nostrum, C.F.; Hennink, W.E. Synthesis and applications of biomedical and pharmaceutical polymers via click chemistry methodologies. Bioconiugate Chem. 2009, 20, 2001-2016.

30. Liu, S.Q.; Ee, P.L.R.; Ke, C.Y.; Hedrick, J.L.; Yang, Y,Y. Biodegradable poly(ethylene glycol)peptide hydrogels with well-defined structure and properties for cell delivery. Biomaterials 2009, 30, 1453-1461.

31. He, X.; Ma, J.; Jabbari, E. Effect of grafting RGD and BMP-2 protein-derived peptide to a hydrogel substrate on osteogenic differentiation of marrow stromal cells. Langmuir 2008, 24 , 12508-12516.

32. Hudalla, G.A.; Murphy, W.L. Using “click” chemistry to prepare SAM substrates to study stem cell adhesion. Langmuir 2009, 25, 5737-5746.

33. Gallant, N.D.; Lavery, K.A.; Amis, E.J.; Becker, M.L. Universal gradient substrates for "click” biofunctionalization. Adv. Mater. 2007, 19, 965-969.

34. Sejwal, P.; Narasimhan, S.K.; Prashar, D.; Bandyopadhyay, D.; Luk, Y.-Y. Selective immobilization of peptides exclusively via $\mathrm{N}$-terminus cysteines by water-driven reactions on surfaces. J. Org. Chem. 2009, 74, 6843-6846. 
35. Parrish, B.; Breitenkamp, R.B.; Emrick, T. PEG- and peptide-grafted aliphatic polyesters by click chemistry. J. Am. Chem. Soc. 2005, 127, 7404-7410.

36. Lutz, J.-F.; Börner, H.G.; Weichenhan, K. Combining ATRP and “click” chemistry: a promising platform toward functional biocompatible polymers and polymer bioconjugates. Macromolecules 2006, 39, 6376-6383.

37. Kinnane, C.R.; Wark, K.; Such, G.K.; Johnston, A.P.R.; Caruso, F. Peptide-functionalized, lowbiofouling click multilayers for promoting cell adhesion and growth. Small 2009, 5, 444-448.

38. Rong, J.; Lee, L.A.; Li, K.; Harp, B.; Mello, C.M.; Niu, Z.; Wang, Q. Oriented cell growth on self-assembled bacteriophage M13 thin films. Chem. Commun. 2008, 5185-5187.

39. Lu, J.; Shi, M.; Shoichet, M.S. Click chemistry functionalized polymeric nanoparticles target corneal epithelial cells through RGD-cell surface receptors. Bioconjug. Chem. 2009, 20, 87-94.

Sample Availability: Not available.

(C) 2010 by the authors; licensee Molecular Diversity Preservation International, Basel, Switzerland. This article is an open-access article distributed under the terms and conditions of the Creative Commons Attribution license (http://creativecommons.org/licenses/by/3.0/). 